\title{
CORRESPONDENCE
}

\section{USE OF A FINE METAL RING IN THE LOCALISATION OF INTRA-OCULAR FOREIGN BODIES}

To the Editors of The BRITISH JouRnal of Ophthalmology.

DEAR SIRS,- In the article by. H. B. Stallard in the Journal for March, 1944, referred to in a letter by L. B. Somerville-Large in the current number a description is given of the use of a fine limbal metal ring and of a method of taking the X-ray photographs.

The purpose of this letter is to state that fixation of the head, the use of a fine metal limbal ring and the method of taking the X-ray photographs described were in routine use in the Sunderland and Durham County Eye Infirmary in 1915. The originator was Alfred Clarence Norman, M.D.(Edin.), who was then House-Surgeon and is now Professor of Radiology in Baghdad.

Yours faithfully,

SCONE PALACE, PERTH,

James A. Ross.

September 9. 1945.

OBITUARY

\section{SIR JAMES BARRETT}

ON April, 6 1945, the dynamic and gifted personality of James William Barrett, K.B.E., passed on. It is fitting now for us to ask, What works he performed and what was the source of his enthusiasm? That he performed works and possessed enthusiasm beyond the average man is undoubted. Humorously it is told of a visitor to Melbourne who, finding the city unduly crowded and asking the cause was told, "The secretary of Sir James, by mistake has called all his committees together on the same day."

Much of interest and not a little inspiration can be drawn from a consideration of his long and useful career. What were the gifts, physical and spiritual that enabled him to do what he did? What was it that lit the fire in his early youth and impelled him " to seek, to strive, to find and not to yield?" Was it his Quaker ancestry, or was it the youth of his native land that fired him? Melbourne had been a city but for twenty-eight years when he was born! In many ways it can be seen that ideas for the betterment of his fellows and of his native land were absorbed early, and they 